\title{
Antonio Brand, el que supo escuchar a los Guaraní
}

\author{
Bartomeu Melià, s.j.*
}

Antonio Brand, a pesar de nuestra amistad de años y en situaciones donde era él la persona principal, siempre me trataba formalmente como "o señor". No me atreví a decirle que fuese conmigo menos formal. Puede parecer una anécdota baladí, pero quiero comenzar por ella para señalar que era una característica del modo de ser de Antonio era su "educación", hacia parte de una forma de relación tradicional y respetuosa, que sin duda venía de sus padres y familia. Era profundamente "educado" con sus superiores, con sus colegas, con los alumnos, con sus amigos, con los indios, con sus contrarios, sí, con sus contrarios y enemigos, con los que pretendían restarle autoridad cuando era vicepresidente el CIMI, con los que lo calumniaban; "educado" en las luchas de "foice no escuro" con los usurpadores de tierras indígenas en Mato Grosso. Esa educación lo revestía de paz, tranquilidad, autenticidad y verdad; no era diplomacia sino modo de ser, su teko, diría un guaraní.

Al amigo Antonio lo conocí en la Villa San Pedro (Dourados), en reuniones y cursos del CIMI; era cuando él estaba haciendo su "noviciado" indigenista en los tekohá - aldeas de los Kaiowá y Guaraní; Antonio escuchaba y aprendía. Y como tantos que se han acercado a los Guaraní se dejaba fascinar por ese modo de ser amable y firme de los esos pueblos, que resistían y persistían en su modo de ser e identidad. Se sentían en aquel tiempo los graves problemas de un mala política de la FUNAI a través de los autoritarios y poco preparados "Chefes de posto", con cuya politiquería había que contar, sintiendo y sufriendo las consecuencias de la tensión provocada entre capitanes, caciques y comunidades, que dificultaban cualquier acción a largo témino. El otro problema era poder entender cómo se había llegado a aquella situación de tanto desamparo de las comunidades. A través de reuniones y jornadas se procuraba encontrar salidas, y Antonio solía ser el organizador dedicado y responsable aunque su actuación era casi invisible.

* Fue el primer secretario del Departamento de Misiones, de la Conferencia Episcopal Paraguaya, desde 1972; Trabajaba desde 1969 junto a los Guaraní de Paraguay, Bolivia, Brasil y Argentina; De 1977 hasta 1990 estuvo en Brasil en la Missäo Anchieta de Mato Grosso y después como coordinador de pastoral Indígena en las cuatro diócesis de Alto Uruguái con los Kaingang y Guarani. De nuevo en Paraguay, a la caída de la dictadura. Recibió en 2011 el Premio Bartolomé de las Casas. Autor de libros y artículos de etnohistoria y lingüística.

Tellus, ano 12, n. 23, p. 231-233, jul./dez. 2012

Campo Grande, MS 
Como coordinador nacional del CIMI, siguió después escuchando en ese inmenso Brasil la verdad de las comunidades amenazadas por la mentira colonial y los intentos de desalojo, y se hizo compañero e intermediario de los indios con la sociedad nacional, una sociedad envolvente nada simpática con esas sociedades indígenas precisamente porque se sabe que son auténticas y necesarias para entender nuestro pasado y nuestro futuro. Por entonces, de 1982 a 1990, dado mi trabajo como coordinador de Pastoral Indígena del Alto Uruguay, me encontraba con él en encuentros y asambleas, donde él tenía ya otras preocupaciones más amplias y complicadas.

Por fin lo encontré en otra forma de escuchar a los indios; él estaba en la universidad y quería saber lo que se decía de los indios en los documentos históricos como camino para entender la situación actual. Preparaba su máster y después su doctorado. A partir de su propia experiencia, el indio de papel, el documentado, dejaba de ser un objeto de estudio, para convertirse en sujeto que vivía una nueva colonia más cruel y perversa, más perversa e inícua, esto era ahora lo científico y real. Le acompañé en su modo de hacer etnohistoria, que no era historia de indios, sino leer la historia como si la escuchara de los mismos indios. Por fin encontró la palabra clave que explica esa triste historia: confinamiento. Los Guaraní y Kaiowá del Mato Grosso estaban confinados en su propio territorio, sin libertad en su propia tierra; ésta era la manera de vivir y sufrir su situación colonial, ahora en el siglo XX. Los Guaraní lo sabían, aunque no tenían los medios para decirlo a esa otra sociedad que había invadido y usurpado sus territorios. Ya profesional con sus títulos de máster y doctorado, lo conocí creativo en proyectos bien planificados y a la vez atrevidos y valientes (corajosos).

Probablemente algún colega se referirá a su obra científica publicada, por cierto muy amplia para un profesor con funciones de coordinación en la universidad, que son en detrimento de un producción más personal. Pero quiero rescatar y poner de relieve su originalidad de visión, raíz y energía para actuaciones concretas en el campo de la justicia indígena y que muy pronto inquietó a los usurpadores del territorio kaiowá y guaraní, pues supo definir en una palabra precisa, única y genial, la situación concreta de los indígenas en Mato Grosso: confinamiento. Sus tesis de máster y doctorado son la explicitación de este drama que ya no puede ocultarse y que cualquier política tiene que tomar en serio:

BRAND, Antonio J. O confinamento e seu impacto sobre os Pãi/Kaiowá. 276p. Disertación (Mestrado en Historia) - Pontificia Universidade Católica do Rio Grande do Sul, Porto Alegre, 1993.

. O impacto da perda da terra sobre a tradição Kaiowá-Guaraní: os difíceis caminhos da palabra. 382p. Tesis (Doctorado) - PUCRS, Porto Alegre, 1997.

Otros temas claves fueron el estudio de los misteriosos suicidios y sobre 
teoría y práctica de una historia guaraní, no la convencional historia de los guaraníes vistos como apéndices de otras historias.

Contribuyó decisivamente a que los propios indios entraran en la Universidad, no los hizo simples repetidores de conocimientos venidos de afuera que debían ser asimilados, sino investigadores y maestros de su propia sabiduría, dispuestos a entrar en diálogo generoso, incluso con quienes han sido tan avaros con ellos y les han negado hasta el saludo; nacía así el gran proyecto, uno de los más creativos y sustentables que conozco: a rede de saberes. Los indios recopilan su sabiduría, la sistematizan, se la comunican entre sí y nos la ofrecen. Este es un precioso legado de Antonio Brand, grande porque no perseguía méritos académicos para sí, sino porque estaba destinado a ser la voz y el canto que los indios hacen escuchar a nuestra sociedad que, de puro gritar y dar órdenes, ha perdido la palabra.

23 diciembre 2012. 
